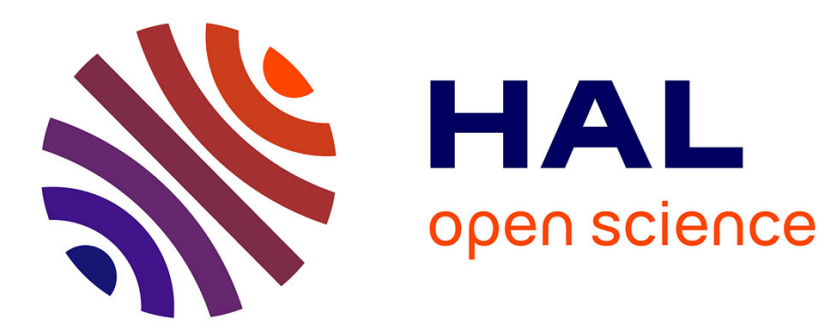

\title{
Investigation into ferrofluid magnetoviscous effects under an oscillating shear flow
}

Marcos Pinho, B. Brouard, Jean-Michel Génevaux, Nicolas Dauchez, O. Volkova, Hervé Mezière, Patrick Collas

\section{- To cite this version:}

Marcos Pinho, B. Brouard, Jean-Michel Génevaux, Nicolas Dauchez, O. Volkova, et al.. Investigation into ferrofluid magnetoviscous effects under an oscillating shear flow. 2011. hal-00598242

\section{HAL Id: hal-00598242 \\ https://hal.science/hal-00598242}

Submitted on 5 Jun 2011

HAL is a multi-disciplinary open access archive for the deposit and dissemination of scientific research documents, whether they are published or not. The documents may come from teaching and research institutions in France or abroad, or from public or private research centers.
L'archive ouverte pluridisciplinaire HAL, est destinée au dépôt et à la diffusion de documents scientifiques de niveau recherche, publiés ou non, émanant des établissements d'enseignement et de recherche français ou étrangers, des laboratoires publics ou privés. 


\title{
Investigation into ferrofluid magnetoviscous effects under an oscillating shear flow
}

\author{
M. Pinho ${ }^{\mathrm{a}}$, B. Brouard ${ }^{\mathrm{a}}$, J. M. Génevaux ${ }^{\mathrm{a}}$, N. Dauchez ${ }^{\mathrm{b}}$, O.Volkova $^{\mathrm{c}}$, H. Mézière ${ }^{\mathrm{a}}$, P. Collas ${ }^{\mathrm{a}}$ \\ ${ }^{a}$ LAUM - Laboratoire d'Acoustique de l'Université du Maine UMR CNRS 6613, France \\ ${ }^{b}$ LISMMA - Institut Supérieur de Mécanique de Paris (SUPMECA), 93407 Saint Ouen, France \\ ${ }^{c}$ Centre de micro et nanorhéométrie, Université de Nice-Sophia Antipolis, Parc Valrose, 06108 Nice-cedex2, France
}

\begin{abstract}
The use of ferrofluid seals in mechanical systems can lead to viscous damping that affects their dynamic behavior. This paper describes an investigation into local viscous properties in the case of an axial harmonic force. The influence of magnetic field level, shear stress amplitude and frequency are studied. Even for ferrofluid particles in a highly saturated magnetic field, it is shown that viscosity increases with magnetic intensity, decreases with the frequency of harmonic excitation and is not sensitive to shear rate amplitude. Viscosity is lower for oscillatory flows than for steady flows.
\end{abstract}

Keywords:

ferrofluids, viscosity measurements, viscosity

47.65.Cb, 83.85.Jn, 66.20.-d

\section{Introduction}

Ferrofluid is a colloidal mixture composed of magnetic nanoparticles suspended in a carrier liquid which becomes polarized in the presence of a magnetic field [1]. Consequently, several properties may be distinguished: it can be confined in a given space by a magnetic field in which its viscosity can be controlled by the intensity of the latter. Ferrofluid has been used in a wide variety of applications for many years: by NASA in the 60s for controlling liquids in space [2], avionics, rotating shaft seals, ball bearings, damping systems, lubrication and loudspeakers $[3,4,5,6,7,8]$. In the latter application,they allow better heat dissipation and guidance of moving parts [7, 8].

The "magnetoviscous effect" characterizes all field-induced changes of viscosity $\Delta \eta$ in concentrated suspensions [9]. In the absence of magnetic field and for a constant shear stress, viscosity is $\eta_{0}$. In the presence of a stationary magnetic field, rigid chain-like structures are formed by the particles in the direction of the field. As a consequence, the carrier fluid is forced to flow around the chains, leading to increased viscosity [10]. This phenomenon was first observed experimentally by McTague [11] in 1969, then explained theoretically by Shliomis [12] in 1972 and expanded by Odenbach [13] in 1998 to commercial ferrofluids with higher particle concentrations and strong inter-particle interactions.

The chains formed are liable to break down in the presence of constant shearing, leading to lower viscosity [13]. The experiments carried out to validate this dependence on viscosity shear rate in a magnetic field have usually been conducted in a rheometer with steady flows (Fig. 1a). However, in some dynamical applications such as ironless loudspeakers [7], ferrofluid seals are affected by mechanical sinusoidal excitation. Thus there may be a difference in the reduction of viscosity between oscillatory shearing and stationary shearing. a)

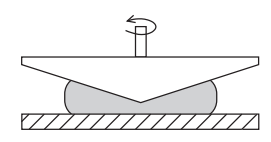

Fixed b)

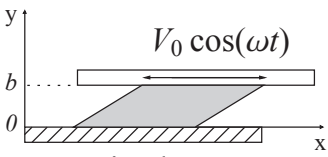

Fixed
Figure 1: Viscosity measurement: a) rotational method, b) parallel planes method.

In the case of particle rotations induced by an oscillating magnetic field, a decrease of viscosity lower than value $H=0$ $\mathrm{kAm}^{-1}$ is observed if the oscillation frequency of the magnetic field is higher than the vorticity of the flow field. This socalled "negative-viscosity" phenomenon was first studied theoretically by Shliomis [14] in 1994 and then verified experimentally by Bacri [15] and Zeuner [16]. Conversely, in the case of a steady magnetic field, the decrease of viscosity may be related to a break in the interaction between particles or chains. To the authors's knowledge, the effects of oscillatory shear flows on ferrofluid viscosity in a steady magnetic field have not been investigated except for a zero magnetic field [18].

The aim of this paper is to measure the viscosity of ferrofluids as a function of steady magnetic field intensity, shear stress amplitude and harmonic excitation frequency. The following section describes the model used to determine the viscosity of the ferrofluid in oscillating movement from the experimental viscous damping of a one degree of freedom system. Section 3 presents the experimental setup. The results are presented and discussed in section 4 . 


\section{Model}

This section presents the theoretical background used to determine fluid viscosity from an oscillatory shear flow between two sliding planes.

The experimental configuration is based on the shearing of a volume of fluid placed between parallel planes [19] separated by distance $b$ (Fig. 1b). The lower plane is at rest. The upper plane, at $y=b$, is subject to harmonic motion in direction $x$. Its velocity is $v_{p}(t)=V_{0} \cos (\omega t)$, where $V_{0}$ is the amplitude, $\omega=2 \pi f$ the angular frequency and $f$ the frequency.

This system is modeled by a one degree of freedom system (Fig. 2). The corresponding dynamic equation is written as

$$
\left(m_{0}+m\right) j \omega v_{p}=-\left(c_{0}(f)+c(H, \dot{\Gamma}, f)\right) v_{p}-\frac{k}{j \omega} v_{p}+F,
$$

where $m_{0}$ is the mass of the moving plane and $c_{0}$ the residual damping of the system without a ferrofluid seal. $m, c$ and $k$ are respectively the added-mass, damping and stiffness coefficients of the ferrofluid volume wetting the moving plane. $c$ is considered to be a function of the magnetic field $H$, the amplitude of the shear rate $\dot{\Gamma}$ at $y=b$ and the frequency $f$. $F$ is the mechanical excitation force.

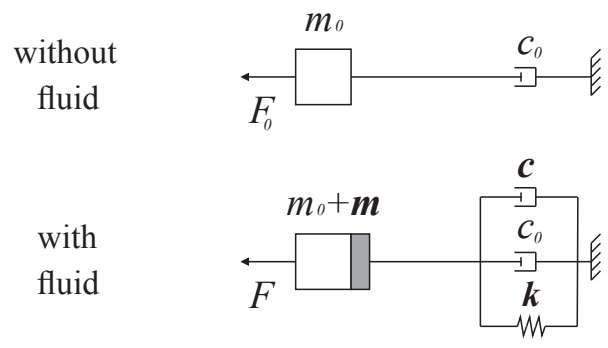

Figure 2: Equivalent one degree of freedom system with and without ferrofluid as a function of the $\mathrm{x}$-direction.

The fluid flow $\mathbf{v}$ is considered unidirectional: $\mathbf{v}=v_{x}(y, t) \mathbf{x}$. The stress continuity at the interface between the plane and fluid gives,

$$
-c v_{p}=-\mathfrak{R} e\left(\int_{A} \sigma_{x y} d A\right)
$$

with $A$ being the area of the contact surface and $\sigma_{x y}=\eta \frac{\partial v_{x}}{\partial y}$. Thus the viscosity is

$$
\eta=\frac{c V_{0}}{\left.A \frac{\partial v_{x}}{\partial y}\right|_{y=b}} .
$$

Note that $\partial v_{x} / \partial y$ depends on the velocity profile. The continuity of velocities at the interface between plane and fluid $\left(V_{0} \cos \omega t=v_{x}(b, t)\right)$ is considered. For a low Reynolds number, the velocity profile is assumed to be linear and independent of the frequency, as shown in Fig.1b,

$$
v_{x}(y, t)=\frac{y}{b} V_{0} \cos (\omega t) \quad, \forall y .
$$

The viscosity is determined from the viscous damping term by:

$$
\eta=c \frac{b}{A} \text {. }
$$

\section{Experimental setup}

This section presents the experimental set-up used to measure ferrofluid viscosity $\eta(H, \dot{\Gamma}, f)$ as a function of magnetic field intensity, shear rate amplitude and harmonic oscillation frequency.

The experimental setup is shown in Fig. 3. One moving plate (5, Fig. 3) is positioned between two plates at rest (3, Fig. 3). All the plates are parallel with each other and horizontal, separated by a gap of thickness $b=0.94 \mathrm{~mm}$. Each gap is filled with the same volume of ferrofluid (4, Fig. 3). The moving plate is excited by an electrodynamic shaker at a stationary frequency between $10 \mathrm{~Hz}$ and $50 \mathrm{~Hz}$, considerably lower than the first resonance frequency of the mechanical assembly. The excitation force is measured by a force sensor (BK 8001) inserted between the shaker and the moving plate. Its sensitivity and seismic mass as function of frequency are determined by using a method with two known masses. The velocity $v$ of the moving plate is measured by a laser vibrometer (Polytech OFV 3000). The velocity amplitude of oscillation $V_{0}$ is kept constant for each step by step frequency sweep. Complex mechanical impedances are obtained from the ratio of force over velocity. The measurement chain is shown in Fig. 4.

A stationary external magnetostatic field can be applied in the $y$ direction by two symmetrically placed identical permanent magnets (Fig. 3). The magnetic field is thus perpendicular to the fluid vorticity and uniform in the gap. Its level can be tuned from $H=0 \mathrm{kAm}^{-1}$ to $H=438 \mathrm{kAm}^{-1}$ by controlling the distance between the magnets and the moving plate. The room temperature was $21.0 \pm 0.5^{\circ} \mathrm{C}$ during the tests.

The measurement procedure is divided into two steps (Fig. 2):

- first, the impedance $F_{0} / v$ is measured without ferrofluid to determine the residual damping,

$$
c_{0}(f)=\mathfrak{R} e\left(\frac{F_{0}(f)}{v(f)}\right),
$$

- then, measurements with ferrofluid are performed. The added damping is given by:

$$
c(H, \dot{\Gamma}, f)=0.5\left[\mathfrak{R} e\left(\frac{F(f)}{v(f)}\right)-c_{0}(f)\right] .
$$

The coefficient 0.5 stems from the utilisation in the experiment of two identical seals.

The ferrofluid is added into the gaps with a syringe to form the seals. The volume of ferrofluid is controlled by weighing the syringe: the mass is $0.100 \mathrm{~g} \pm 0.005 \mathrm{~g}$ for a volume of $76.3 \mathrm{~mm}^{3}$. The surface of the ferrofluid in contact with each plate is $81.2 \mathrm{~mm}^{2}$.

Two commercial ferrofluids produced by Ferrotec are used: APGW05 $\left(\eta_{0}=0.72\right.$ Pa.s; $\left.\rho=1330 \mathrm{kgm}^{-3}\right)$ and APGW10 $\left(\eta_{0}=1.53\right.$ Pa.s; $\left.\rho=1310 \mathrm{kgm}^{-3}\right)$. Both have the same saturation magnetization of $32 \pm 10 \mathrm{kAm}^{-1}$. They differ mainly by their viscosity due to the properties of the synthetic ester carrier liquid. 


\section{Results and discussion}

\section{Shaker Force sensor}

a)

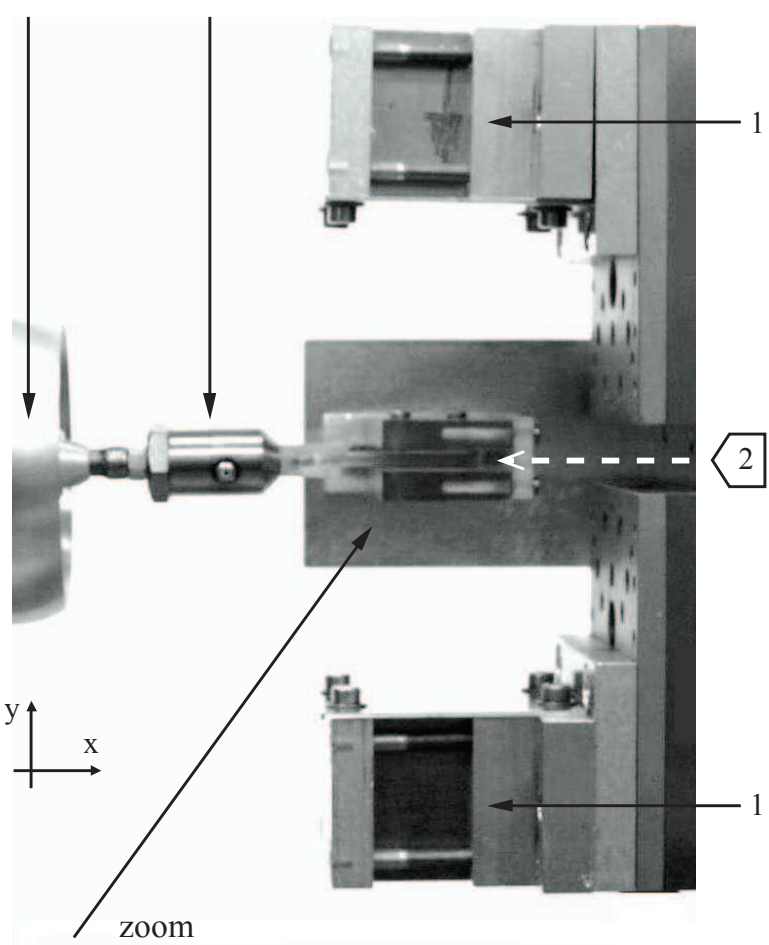

b)

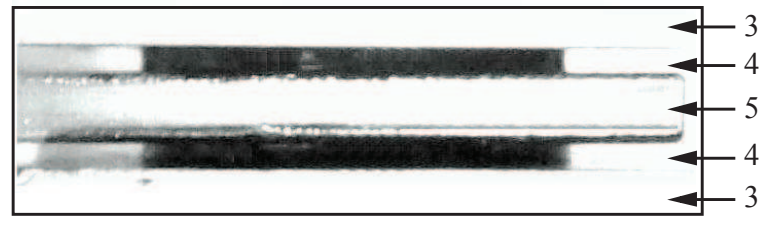

Figure 3: a) Experimental setup: 1. permanent magnets; 2. laser vibrometer; b) zoom of the ferrofluid region: 3 . still plates at rest; 4 . ferrofluid seals; 5 . moving plate.

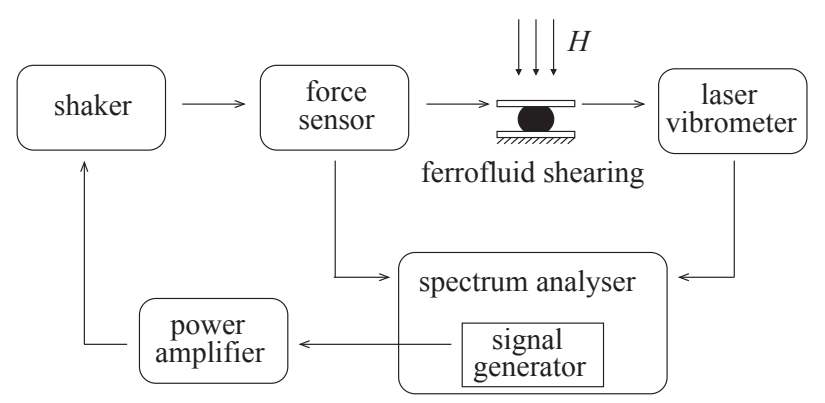

Figure 4: Measurement chain.
Viscous damping $c$ is measured as a function of frequency for eight magnetic field levels. Results are evaluated for three shear rate amplitudes $\dot{\Gamma}: 5 \mathrm{~s}^{-1}, 15 \mathrm{~s}^{-1}$ and $25 \mathrm{~s}^{-1}$. Viscous damping with APGW10 at $\dot{\Gamma}=25 \mathrm{~s}^{-1}$ is given in Fig. 5 as example. Viscosity can also be obtained by using eq. 5 since the maximum Reynolds number $R e_{\max } \leq 0.1$ obtained under our conditions. This results in a laminar flow profile between the plates.

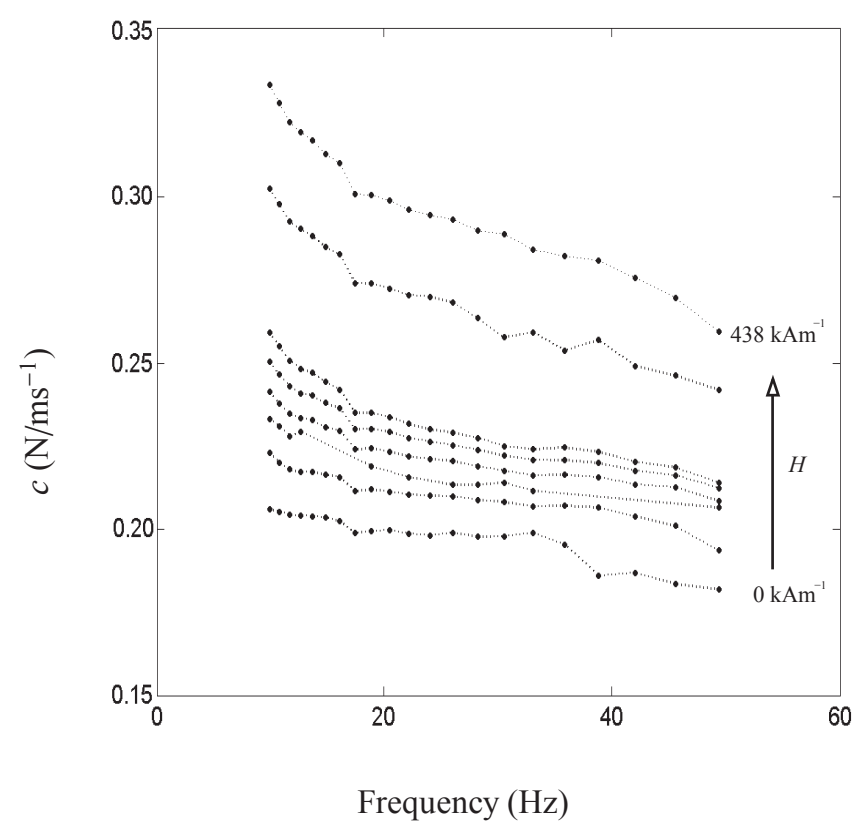

Figure 5: Viscous damping $c\left(H, \dot{\Gamma}=25 \mathrm{~s}^{-1}, f\right)$ measured for eight magnetic fields levels (in $\mathrm{kAm}^{-1}$ ): $0,18,21,25,29,36,177$ and 438 .

Fig. 6 shows viscosity as a function of the frequency for three shear rate amplitudes and three magnetic field levels. Viscosity is independent of the shear rate amplitude whatever the magnetic field level. The instantaneous shear rate oscillates, going from zero to the extremal values of of $\dot{\gamma}_{\max }=\dot{\Gamma}=5 \mathrm{~s}^{-1}, 15 \mathrm{~s}^{-1}$ or $25 \mathrm{~s}^{-1}$. Although this can be considered as a high shear rate for which no change of viscosity with the magnetic field appears [20], the shear thinning effects do not appears. With the rotational test $[13,17]$, the destruction of the chain due to the level of fluid shearing is associated with the shear rate amplitude. For alternating movement, the results suggest that this rupture occurs at each cycle and that the oscillation amplitude plays no role. In the latter case, fluid shearing is correlated to the frequency of oscillation as shown in Fig.6 in which viscosity can be seen to decrease with frequency. This behavior is observed for both ferrofluids (Fig.7).

Fig. 8 shows the viscosity as a function of magnetic field intensity. It can be observed that the higher the intensity of the magnetic filed, the higher the viscosity. This is coherent with Thurm and Odenbach [21] results, obtained for smaller magnetic field at $f=0 \mathrm{~Hz}$, smaller shear rates and ferrofluids using different fractions of larger particles. It can be observed 


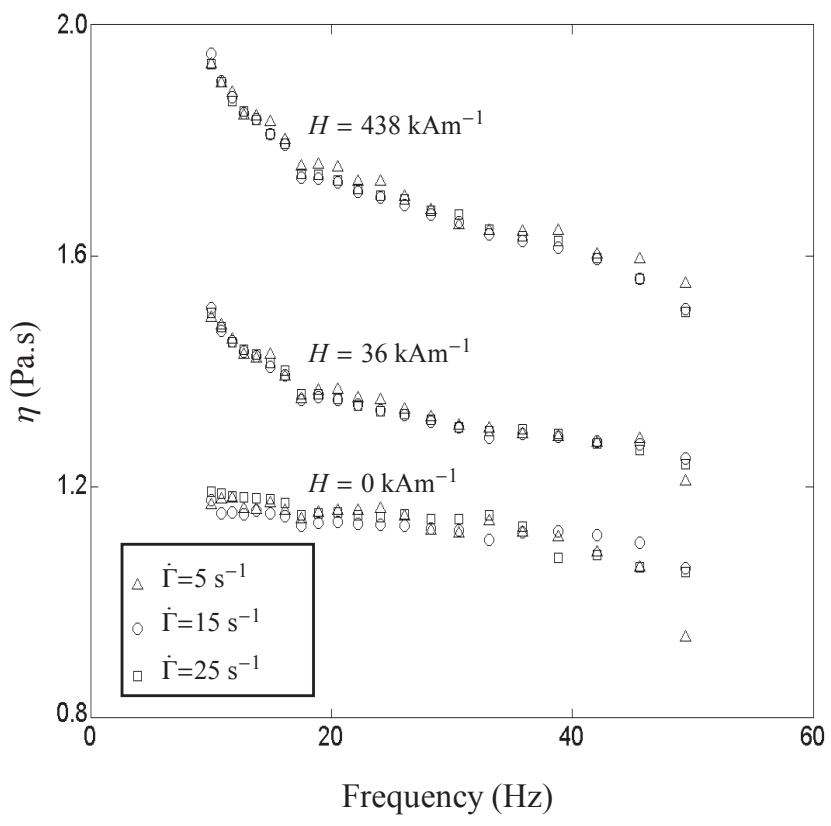

Figure 6: The viscosity dependence $\eta(H, \dot{\Gamma}, f)$ of APGW10 on oscillating shear rate under a steady magnetic field.

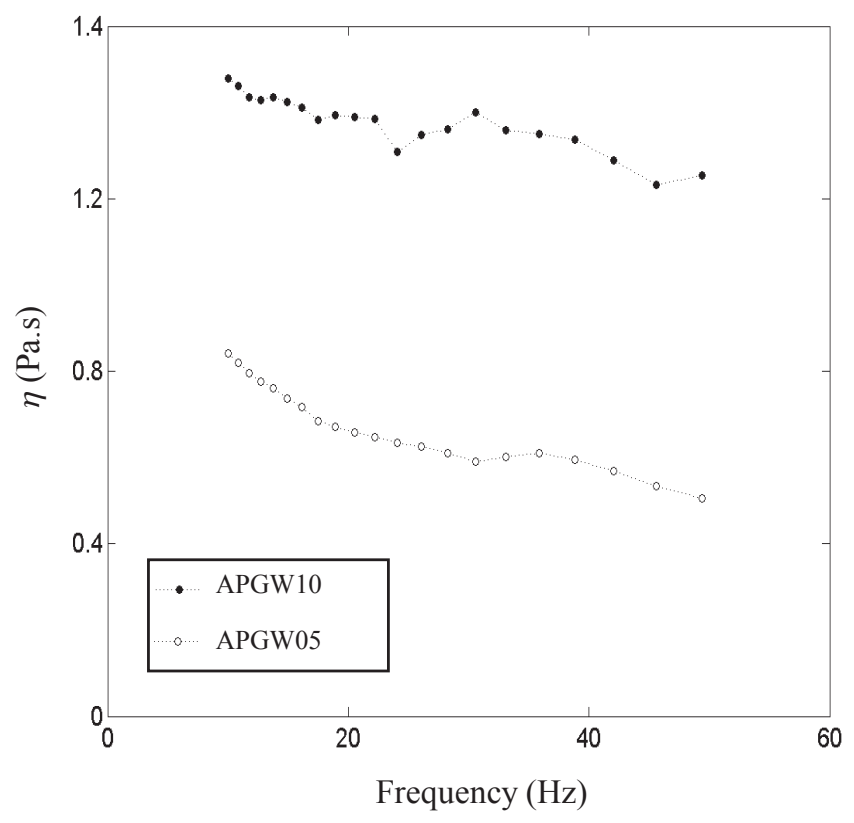

Figure 7: Experimental viscosity of two samples of ferrofluid $\eta(H=48$ $\left.\mathrm{kAm}^{-1}, f\right)$. that the higher the intensity of the magnetic fields, the higher the viscosity.

The previous results are now compared with steady flow measurements $(f=0 \mathrm{~Hz})$ obtained with a rheometer. The viscosity of APGW10 was determined for three magnetic field levels and constant shear rates of the same order as in the alternating measurements. The values are presented in a reduced viscosity form (Fig. 9) with the reference value $\eta(0,0)=1.5 \mathrm{~Pa}$ s:

$$
\frac{\Delta \eta}{\eta_{0}}=\frac{\eta(H, f)-\eta(0,0)}{\eta(0,0)} .
$$

With the decrease of frequency $(f \rightarrow 0 \mathrm{~Hz})$, the relative viscosity tends to that obtained under steady flow conditions.

A negative variation of viscosity $\Delta \eta$ is observed. Note that for $H=0 \mathrm{kA} \mathrm{m}^{-1}$, the negative variation of viscosity is in the order of $30 \%$. The curves obtained here are consistent with the "negative-viscosity effect" described by the particle interaction theory [14]: particle rotation is accelerated by the oscillation of either the magnetic or the mechanical field.

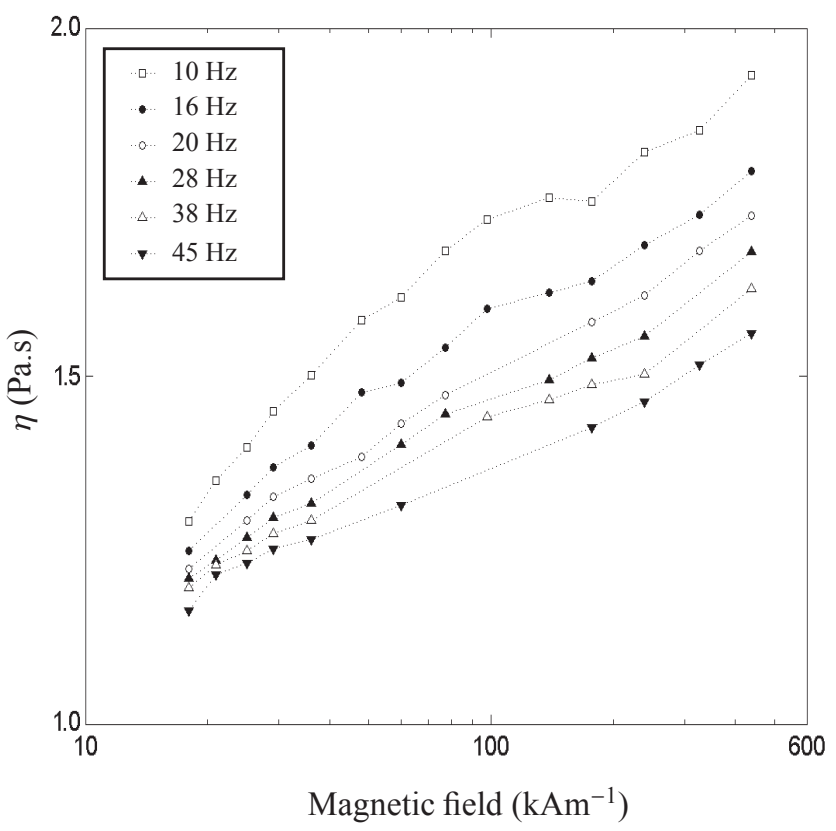

Figure 8: Experimental viscosity $\eta(H, f)$ of APGW10 for different levels of oscillation frequency in a steady magnetic field.

\section{Conclusions}

The viscosity of two ferrofluids was measured under oscillating shear flow conditions from $0 \mathrm{~Hz}$ to $50 \mathrm{~Hz}$ and in a steady magnetic field ranging in intensity from $0 \mathrm{kAm}^{-1}$ to $438 \mathrm{kA} \mathrm{m}^{-1}$. It is shown that viscosity increases with the intensity of the magnetic field, decreases with shearing frequency and is not sensitive to shear rate amplitude.

Ferrofluid viscosity was found to be lower for oscillatory than for steady flow shearing. Negative-viscosity effect for a stationary magnetic field occurs even for a null magnetic field. 


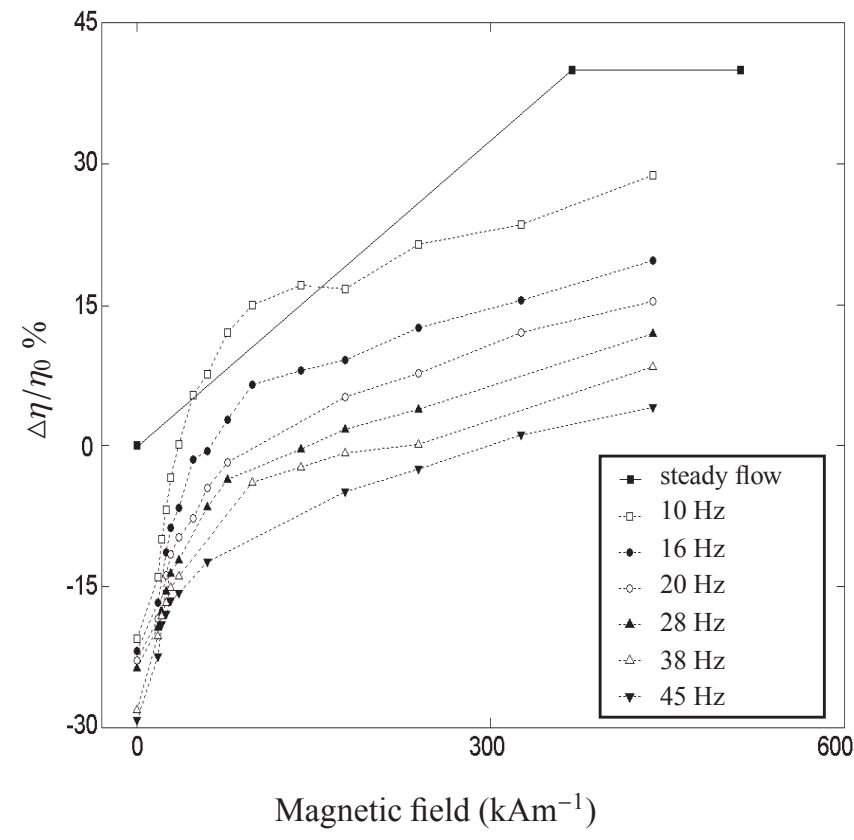

Figure 9: Dependence of the relative viscosity changes of a ferrofluid seals in oscillating movement in a steady magnetic field.

The results suggest that the chain-like structures created by the magnetic field are broken twice per oscillation cycle, i.e. every moment the fluid is not at rest.

These results will be used for modeling a new type of loudspeaker whose moving parts are guided by ferrofluid seals [8].

\section{Acknowledgements}

The authors are grateful to the Région Pays de la Loire for its financial support.

\section{References}

[1] R.E. Rosensweig, Ferrohydrodynamics, Cambridge University Press, Cambridge, 1985.

[2] H. Yamaguchi, Engineering Fluid Mechanics, Springer, Dordrecht, 2008.

[3] K. Raj, R. Moskowitz, J. Magn. Magn. Mater. 85 (1990) 233.

[4] S. Odenbach, Colloidal Magnetic Fluids: Basics, Development and Application of Ferrofluids, Springer, Berlim, 2009.

[5] P. Khuzir, Tribol. Int. 41 (2008) 256.

[6] R.E. Rosensweig, Y. Hirota, S. Tsuda, K. Raj, J. Phys.: Condens. Matter 20 (2008) 204147.

[7] G. Lemarquand, IEEE Trans. Magn. 43 (2007) 3371.

[8] R. Ravaud, M. Pinho, G. Lemarquand, N. Dauchez, J.M. Génevaux, V. Lemarquand, B. Brouard, IEEE Trans. Magn. 45 (2009) 4388.

[9] S. Odenbach, Magnetoviscous Effects in Ferrofluids, Springer, Berlin, 2002.

[10] A.P. Krekhov, M.I. Shliomis, S. Kamiyama, Phys. Fluids 17 (2005) 033105 .

[11] J.P. McTague, J. Chem. Phys. 51 (1969) 133.

[12] M.I. Shliomis, Sov. Phys. JETP 34 (1972) 1291.

[13] S. Odenbach, H. Stork, J. Magn. Magn. Mater. 183 (1998) 188

[14] M.I. Shliomis, K.I. Morozov, Phys. Fluids 6 (8) (1994) 2855.

[15] J.C. Bacri, R. Perzynski, M.I. Shliomis, G.I. Burde, Phys. Rev. Lett. 75 (1995) 2128.
[16] A. Zeuner, R. Richter, I. Rehberg, Phys. Rev. E 58 (1998) 6287.

[17] H.W. Muller, Phys. Rev. Lett. 82 (1999) 3907.

[18] Y. Yamada, Y. Enomoto, J. Phys. A 387 (2008) 1.

[19] F. Ding, A.J. Giacomin, R.B. Bird, C.B. Kweon, J. Non-Newton. Fluid Mech. 86 (1999) 59.

[20] L.M. Pop, S. Odenbach, A. Wiedenmann, N. Matoussevitch, H. Bönnemann, J. Magn. Magn. Mater. 289 (2005) 303.

[21] S. Thurm, S. Odenbach, Phys. Fluids 15 (2003) 1658 